\title{
Determination of Optimum Frame Rates for Observation of Construction Operations from Time-Lapse Movies
}

\author{
Y. M. Ibrahim 1 , A. D. Ibrahim², and P. G. Chindo ${ }^{3}$ \\ ${ }^{1}$ Senior Lecturer, Department of Quantity Surveying, Ahmadu Bello University, Zaria, Nigeria, E-mail: \\ makarfi@gmail.com (corresponding author). \\ ${ }^{2}$ Senior Lecturer, Department of Quantity Surveying, Ahmadu Bello University, Zaria, Nigeria, E-mail: \\ adibrahim2@yahoo.com \\ ${ }^{3}$ Lecturer, Department of Quantity Surveying, Ahmadu Bello University, Zaria, Nigeria, E-mail: pcgangas@yahoo.com
}

Project Management

Received November 20, 2011; received revisions January 3, 2012; January 13, 2012; accepted January 17, 2012

Available online March 5, 2012

\begin{abstract}
Construction professionals have been using time-lapse movies in monitoring construction operations. However, some amount of detail is always lost in the interval between two consecutive frames in a time-lapse movie. This poses the question: By how much can the frame rate be lowered from the standard 30fps (frames per second) to allow for the accurate observation of construction operations from a time-lapse movie? This paper addresses the problem by establishing the optimum frame rates for observation of activities related to mortar mixing and block handling. The activities were first recorded at the standard rate of 30fps. Using the Adobe Premier Pro video editing software, the records were then segregated into still images from which 15 different time-lapse movies of various time intervals were generated. The movies were then shown to 25 Construction Managers. A structured questionnaire was employed to capture the level of accuracy with which Construction Managers could interpret the job site situation from each movie. The results suggest that $1 \mathrm{fpm}$ (frame per minute) is sufficient for the accurate tracking of labourers involved in mortar mixing while 1 frame in every 20 seconds is sufficient for accurate identification of number of cement bags used. However, for tracking number of blocks off-loaded, and those damaged, 1 frame in every 2 seconds is required.
\end{abstract}

Keywords: Time-lapse movies, construction, operations, optimum, frame rate.

\section{Introduction}

It is estimated that the sense of sight contributes to as much as $75 \%$ of individual's knowledge, while hearing is rated at only about $13 \%$ (Turk, 2001). Hence, construction professionals have been using photographs and movies for documentation and analysis of construction activities since the early 1900's. Several such applications have been reported in literature. The most common applications are in communication of design intent, animation of the virtual world, planning and scheduling, and teaching and learning of construction operations (Bouchlaghem et al, 2005; Chau et al, 2005; Sampaio and Henriques, 2007; Staub-French and Khanzode, 2007). Other applications are in site security and progress monitoring (Sidawi, 2012).

In spite of their valuable applications, video sequences have one major drawback when used to record and document construction operations. This has to do with the fact that it takes an equal amount of time to view the video sequence, as the time taken to make the recording. This presents a significant challenge since construction projects can run for years. In order to address this problem, construction operations are recorded by taking still images at selected time intervals. This means recording at a frame rate lower than the standard 30fps (frames per second) established by the National Standard Television Committee. The recorded sequence can then be viewed at the standard frame rate during playback, thereby reducing viewing time. A movie so recorded is said to be in timelapse mode (Everett et al., 1998). In this way, one can watch a ten-hour movie recorded at $1 \mathrm{fps}$ in just 20 minutes. Essentially, tmie lapse photography is a cinematography technique whereby each picture is captured at a rate much slower than it will be played back. When played at normal speed, time appears to be moving faster and thus lapsing. Abeid and Arditi (2002b) gave a useful description of the fundamentals of time-lapse digital photography.

The main application of time-lapse movies is in progress monitoring. Everett et al. (1998) emphasised the use of time-lapse in the monitoring of entire construction operations. They concluded that this approach can be of great benefit in documenting actual project progress and the recordings can be used in the resolution of claims and disputes, for education, public relations, fund raising, and it provides managers with remote access to project progress. The use of time-lapse has been widely employed in monitoring construction projects successfully (Abeid 
and Arditi, 2002a; Abeid and Arditi, 2003; Abeid et al., 2003).

However, there is an issue that needs to be addressed in the use of time-lapse videos. This relates to the fact that lowering the frame rate during recording has an implication for the amount of detail that can be observed from the time-lapse video. This is particularly so because some amount of detail is always not recorded within the interval between any two consecutive frames. The frame rate therefore has an effect on the level of accuracy in interpreting time-lapse videos. This situation raises a question regarding the optimum frame rate required for the observation of various construction operations.

Studies have come up with different frame rates for the observation of construction operations. Everett et al. (1998) alluded that an interval frame rate of $1 \mathrm{fps}$ to $1 \mathrm{fp} 5 \mathrm{~s}$ (i.e. 1 frame per 5 seconds) is most common for the observation of construction activities. However, the basis for this is not clear. Abeid and Arditi (2002b) recommend recording the operation at $1 \mathrm{fps}$ (frames per minute) and playing back time-lapse movies at lower frame rates depending on the need. Their study recognises that the observation of different operations requires different amount of detail and hence, different frame rates. But it fails to come up with the best frame rate required for the accurate observation of each operation. Kang and Choi (2005) studied the error in observation of time-lapse movies using different frame rates and concluded that a time-lapse photo sequence of less than 60-second (1fpm) interval may be used for monitoring construction operations and evaluating productivity with a $70 \%$ level of confidence. However, the study only examined worker productivity.

In summary, several efforts geared towards establishing the best frame rate for the observation of construction operations have been reported but none of these focused on individual activities. This study therefore seeks to establish the optimum frame rate for the observation of manual mixing of mortar and off-loading of blocks.

\section{Research Methods}

First, mortar mixing and block offloading operations were recorded at standard frame rate (30fps) using a digital video camera. The video was then imported into adobe premier pro (a picture and video editing software) and converted into still pictures. 15 different time-lapse movies were then generated at $5 \mathrm{fpm}, 4 \mathrm{fpm}$, $3 \mathrm{fpm}, 2 \mathrm{fpm}$, $1 \mathrm{fpm}$, 50fps, 40fps, 30fps, 20fps, 10fps, 5fps, 4fps, 3fps, $2 \mathrm{fps}$ and $1 \mathrm{fps}$. For the $5 \mathrm{fpm}$ movie, for example, one photo out of every 9000 consecutive images was selected manually and then combined sequentially to produce the time-lapse movie.

In order to identify the relationship between the frame rate of the time-lapse movies and the amount of errors one could make in interpreting the job site situation, the 15 different movies for each activity were shown to 25 construction Managers. For each movie, the respondents were asked to answer questions related to the activity. This was done using a structured questionnaire. In order not to introduce bias, respondents were shown the movies starting from the $5 \mathrm{fpm}$ movie through to the $1 \mathrm{fps}$ movie. Notice that the $5 \mathrm{fpm}$ movie has the least amount of detail while the $1 \mathrm{fps}$ movie has the highest amount of detail.

In order to establish the level of accuracy in interpreting the job site situation for each frame rate, scores were assigned to the responses such that 5 (most accurate) is the highest score and 1 the lowest score. Assume for example that the number of cement bags used in mixing mortar in a time-lapse video is 2 . The respondents who chose 1 and 3 as the number of cement bags used were given a score of 4 (inaccurate by 1 ) as they are close to 2 . Those who chose 0 or 4 bags were given a score of 2 while those who chose 5 or more bags were given a score of 1 .

\section{Results and Discussions}

Table 1 is an example, showing computation of the average scores of five respondents on the number of wheel barrow measures of sand used from the $5 \mathrm{fps}$ time-lapse movie for mortar mixing. All the respondents scored 4 (accurate minus 1) on the number of wheel barrow measures of sand used in mixing mortar. Hence, the average score for all the respondents on their ability to identify the number of wheel barrow measure of sand is 4 .

The same procedure was followed to calculate the average scores for all respondents for the different timelapse movies. However, for the sake of brevity, only a summary of the averages is shown on Table 2.

Table 1. Scores of 5 respondents on 5 minutes interval time-lapse movie in mortar mixing process

\begin{tabular}{cc}
\hline Respondents & $\begin{array}{c}\text { How many wheel barrow measures of sand } \\
\text { were used? }\end{array}$ \\
\hline 1 & 4 \\
3 & 4 \\
4 & 4 \\
5 & 4 \\
\hline Average score & 4 \\
\hline
\end{tabular}




\begin{tabular}{|c|c|c|c|c|c|c|c|c|c|c|c|c|c|c|c|c|}
\hline \multicolumn{17}{|c|}{ Average accuracy scores } \\
\hline $\mathrm{S} / \mathrm{NO}$ & Questions & $\begin{array}{c}5 \\
\text { Min }\end{array}$ & $\begin{array}{c}4 \\
\text { Min }\end{array}$ & $\begin{array}{c}3 \\
\text { Min }\end{array}$ & $\begin{array}{c}2 \\
\text { Min }\end{array}$ & $\begin{array}{c}1 \\
\text { Min }\end{array}$ & $\begin{array}{l}50 \\
\text { Sec }\end{array}$ & $\begin{array}{l}40 \\
\text { Sec }\end{array}$ & $\begin{array}{l}30 \\
\text { Sec }\end{array}$ & $\begin{array}{l}20 \\
\text { Sec }\end{array}$ & $\begin{array}{l}10 \\
\text { Sec }\end{array}$ & $\begin{array}{c}5 \\
\text { Sec }\end{array}$ & $\begin{array}{c}4 \\
\text { Sec }\end{array}$ & $\begin{array}{c}3 \\
\text { Sec }\end{array}$ & $\begin{array}{c}2 \\
\text { Sec }\end{array}$ & $\begin{array}{c}1 \\
\text { Sec }\end{array}$ \\
\hline 1 & $\begin{array}{c}\text { How many wheel barrow measures of sand were } \\
\text { used? }\end{array}$ & 4 & 4 & 4 & 4.2 & 4.8 & 5 & 5 & 5 & 5 & 5 & 5 & 5 & 5 & 5 & 5 \\
\hline 2 & $\begin{array}{c}\text { How many bags of cement were used in mixing } \\
\text { the mortar? }\end{array}$ & 4.2 & 4 & 4 & 4 & 4 & 4 & 4.8 & 4 & 5 & 5 & 5 & 5 & 5 & 5 & 5 \\
\hline 3 & $\begin{array}{l}\text { How many labourers were involved in measuring } \\
\text { sand? }\end{array}$ & 5 & 5 & 5 & 5 & 5 & 5 & 5 & 5 & 5 & 5 & 5 & 5 & 5 & 5 & 5 \\
\hline 4 & $\begin{array}{l}\text { How many labourers were involved in dry } \\
\text { mixing mortar? }\end{array}$ & 5 & 5 & 5 & 5 & 5 & 5 & 5 & 5 & 5 & 5 & 5 & 5 & 5 & 5 & 5 \\
\hline 5 & $\begin{array}{l}\text { How many labourers were involved in wet } \\
\text { mixing? }\end{array}$ & 5 & 4.8 & 5 & 5 & 5 & 5 & 5 & 5 & 5 & 5 & 5 & 5 & 5 & 5 & 5 \\
\hline 6 & $\begin{array}{l}\text { How many wheel barrow measures of mortar } \\
\text { were transported to point of use? }\end{array}$ & 4 & 4.5 & 4 & 4 & 5 & 5 & 5 & 5 & 5 & 5 & 5 & 5 & 5 & 5 & 5 \\
\hline
\end{tabular}

Table 2. Summary of total average scores in various time-lapse movies of mortar mixing 
Fig. 1 shows the trend in the level of accuracy attained in determining the number of wheel barrow measures of sand, as the frame rate increases. Notice that the average score for the 5, 4 and 3 minutes time-lapse movie remained at 4 until it reached the 2 minutes movie when it rose to 4.2 . The score rose to 4.8 in the 1 minute video and then attained the maximum score of 5 in the 50 seconds movie. This remained constant in the rest of the movies. Hence, for measurements using wheel barrows, or any similar activities, the movie should be recorded at 1 frame every 50 seconds.

Fig. 2 reports on the count of number of bags of cement used. It shows how the accuracy in determining the actual number of bags of cement used varies with changing frame rates. The average score for the number of cement bags used was constant at 4 until it reached the 40 seconds interval time-lapse movie where it rose significantly to 4.8 and thereafter dropped to 4 in the 30 seconds interval time-lapse movie. It then rose to the maximum score of 5 (accurate) for the 20 seconds interval time-lapse movie and maintained that level throughout. This implies that the number of cement bags used can be accurately observed from a movie recorded at 1 frame every 20 seconds.

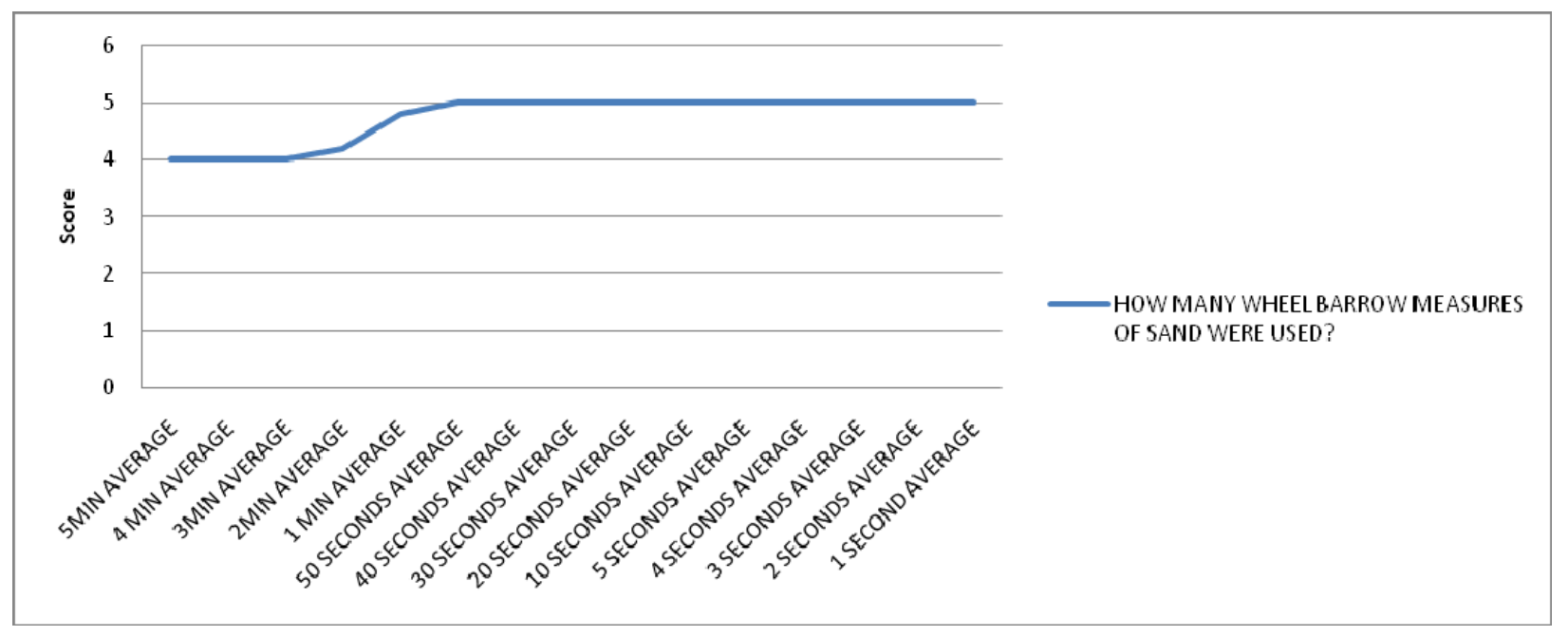

Fig. 1. Number of wheel barrow measures of sand used

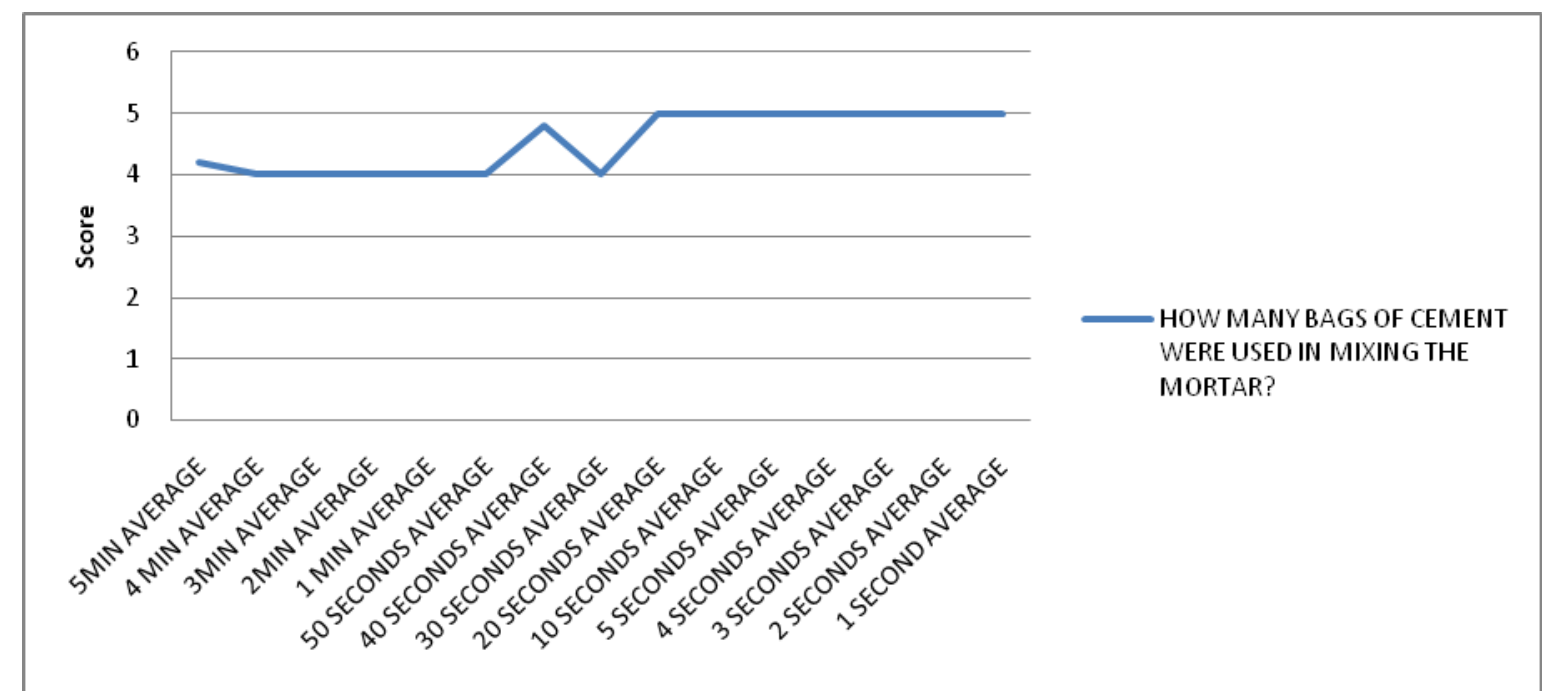

Fig. 2. Number of bags of cement used in mixing mortar 
Figs. 3, 4 and 5 show the accuracy levels obtained in identifying the number of labourers involved in measuring sand, dry mixing and wet mixing of mortar respectively. As for the number of labourers involved in measuring sand, the accuracy level remained constant (accurate) for all the time-lapse movies. Hence, the number of labourers involved in measuring sand can be identified from a movie recorded at 1 frame every 5 minutes. The result is the same for the number of labourers involved in dry mixing (Fig. 4). However, for wet mixing of mortar, the result (Fig. 5) suggests that the number of labourers involved cannot be accurately identified from a 4 minute interval movie. It is clear that this is an outlier since an accurate count was established from the 5 minute interval movie. In reality, the 5 minute interval movie has lower amount of detail than the 4 minute interval video. It can therefore be concluded that the number of labourers can be accurately identified from a movie recorded at 1 frame every 5 minutes.

Fig. 6 shows how the accuracy level for identifying the number of wheel barrow measure of mortar varies with different frame rates. It fluctuates between 4 and 5 until the 1 minute interval time-lapse movie where it attained the stable value of 5 . The maximum score was then maintained down to the 1second interval time-lapse photo video. This indicates that wheel barrow measures of mortar can be accurately observed from a movie recorded at 1 frame every minute.

In a similar way to the analysis of activities related to mortar mixing, activities related to off- loading of blocks were analysed. Table 3 shows the average accuracy scores for the different activities.

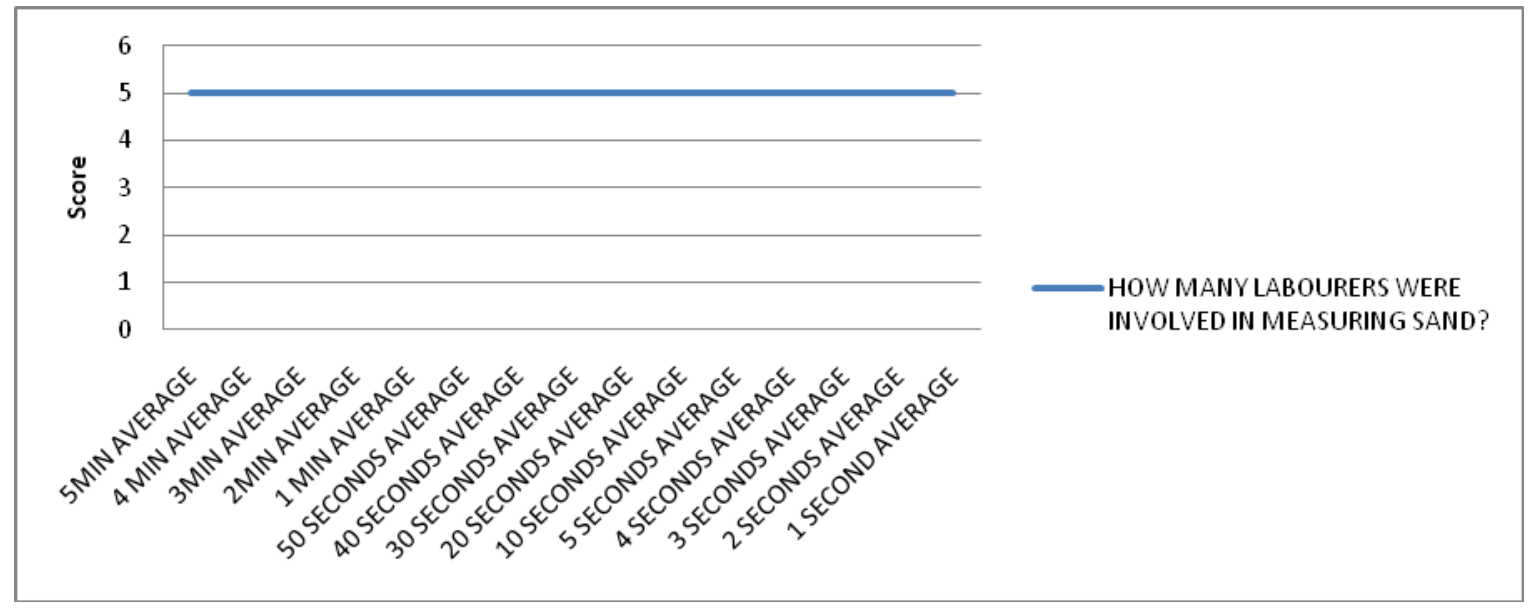

Fig. 3. Number of labourers involved in measuring sand

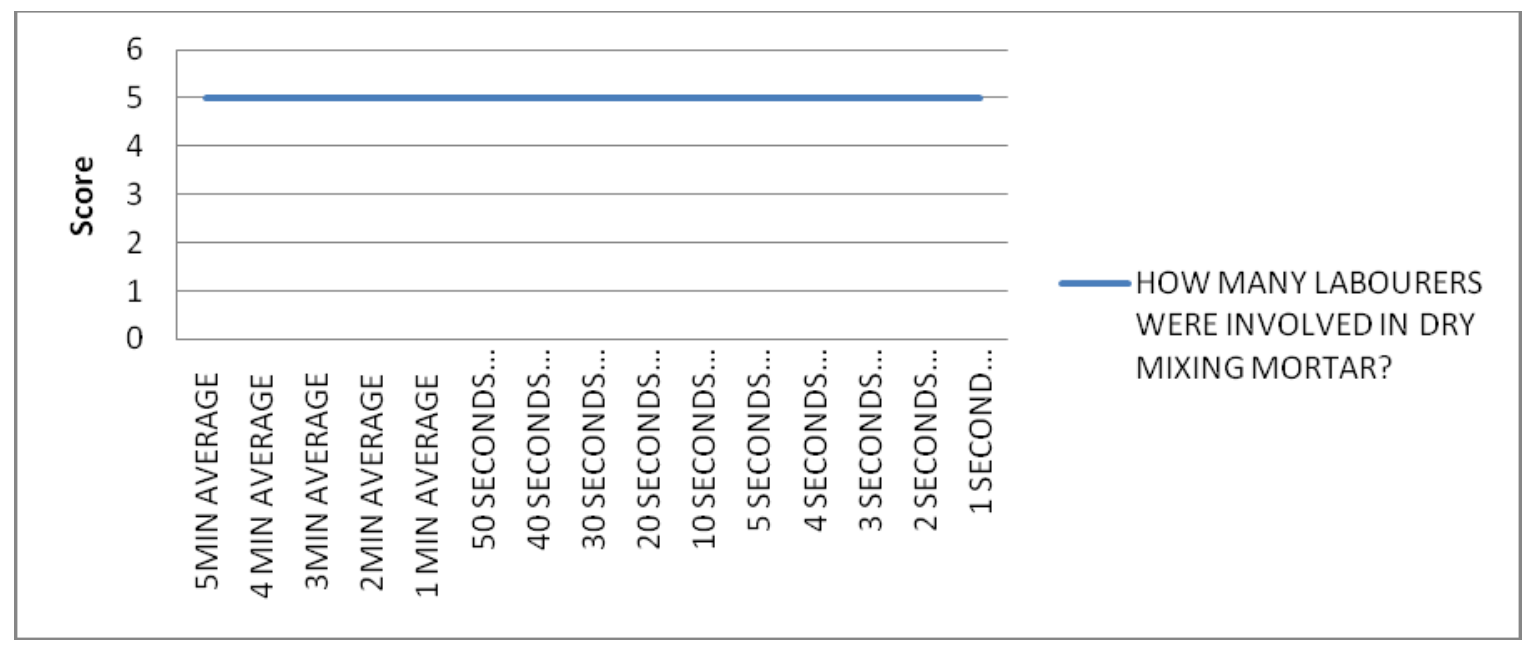

Fig. 4. Number of labourers involved in dry mixing 
62 Y. M. Ibrahim, A. D. Ibrahim, and P. G. Chindo

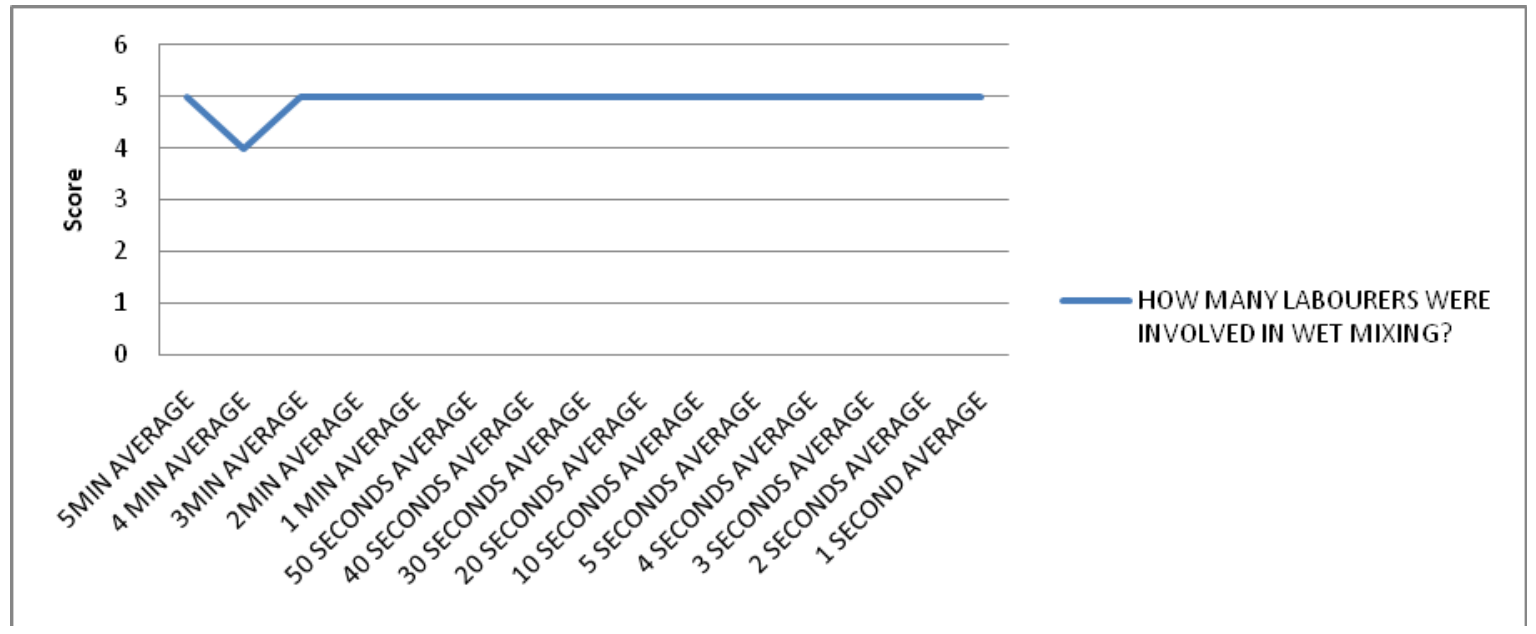

Fig. 5. Number labourers involved in wet mixing

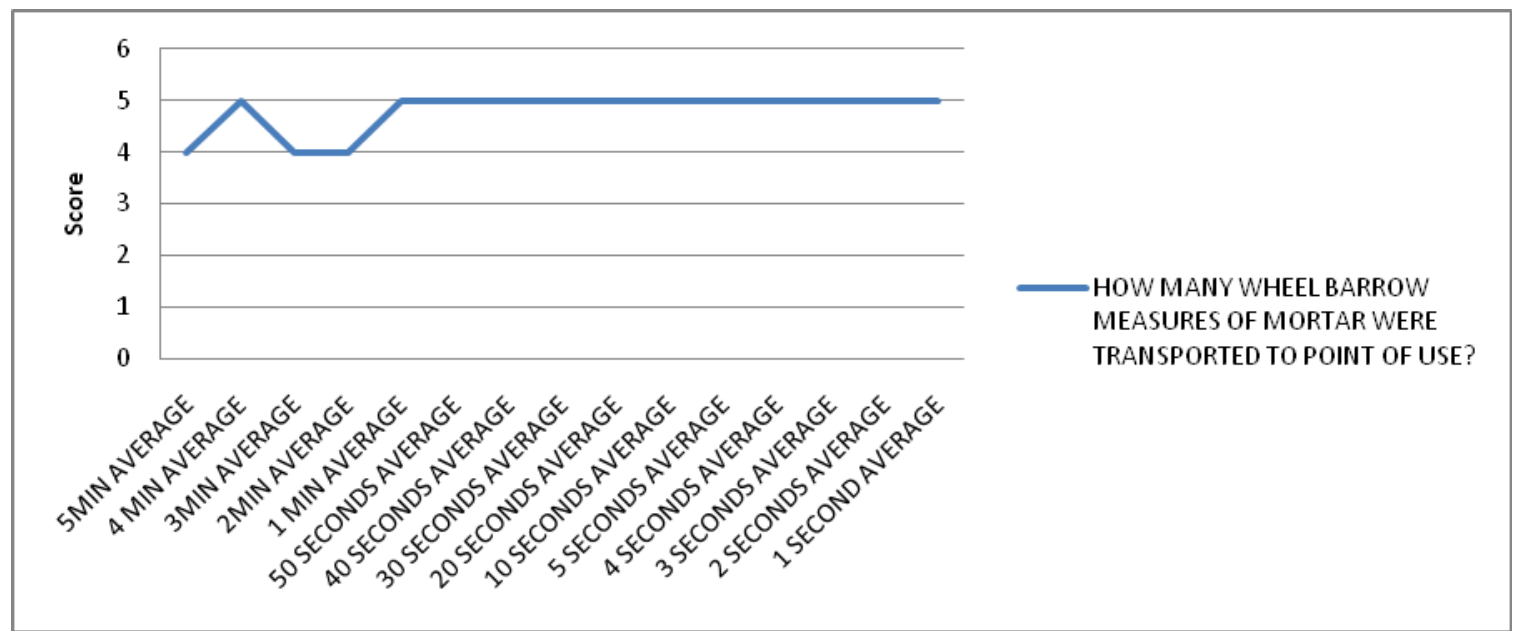

Fig. 6. Number of wheel barrow measures of mortar transported to point of use

Table 3. Summary of total averages in various time-lapse movies in offloading blocks process

\begin{tabular}{|c|c|c|c|c|c|c|c|c|c|c|c|c|c|c|c|c|}
\hline $\mathrm{S} / \mathrm{NO}$ & Questions & $\begin{array}{c}5 \\
\text { Min }\end{array}$ & $\begin{array}{c}4 \\
\text { Min }\end{array}$ & $\begin{array}{c}3 \\
\text { Min }\end{array}$ & $\begin{array}{c}2 \\
\text { Min }\end{array}$ & $\begin{array}{c}1 \\
\text { Min }\end{array}$ & $\begin{array}{l}50 \\
\text { Sec }\end{array}$ & $\begin{array}{l}40 \\
\text { Sec }\end{array}$ & $\begin{array}{l}30 \\
\text { Sec }\end{array}$ & $\begin{array}{l}20 \\
\text { Sec }\end{array}$ & $\begin{array}{l}10 \\
\text { Sec }\end{array}$ & $\begin{array}{c}5 \\
\text { Sec }\end{array}$ & $\begin{array}{c}4 \\
\text { Sec }\end{array}$ & $\begin{array}{c}3 \\
\text { Sec }\end{array}$ & $\begin{array}{c}2 \\
\text { Sec }\end{array}$ & $\begin{array}{c}1 \\
\text { Sec }\end{array}$ \\
\hline 1 & $\begin{array}{l}\text { How many labourers were } \\
\text { involved in offloading the } \\
\text { blocks }\end{array}$ & 4.5 & 4.6 & 4.8 & 5 & 5 & 5 & 5 & 5 & 5 & 5 & 5 & 5 & 5 & 5 & 5 \\
\hline 2 & $\begin{array}{l}\text { How many blocks were } \\
\text { offloaded from the trolley? }\end{array}$ & 2 & 2 & 2 & 2.4 & 2.6 & 2.2 & 2.2 & 3 & 3.4 & 3.4 & 4.2 & 4.4 & 5 & 5 & 5 \\
\hline 3 & $\begin{array}{l}\text { How many blocks were } \\
\text { damaged }\end{array}$ & 4 & 4 & 4 & 4 & 4 & 4 & 4 & 4 & 4 & 4.2 & 4.2 & 4.2 & 4.6 & 5 & 5 \\
\hline
\end{tabular}


As shown on Fig. 7, the accuracy level for identifying the number of labourers involved with offloading of block fluctuates between 4 and 5 until the 2 minute interval movie where it reached the maximum of 5 and remained as such for the rest of the movies. Hence, the number of labourers can be accurately determined from a movie recorded at 1 frame every 2 minutes.

Fig. 8 shows the accuracy in identifying the number of blocks offloaded for the various time-lapse movies. The trend is generally in the upward direction, reaching the maximum accuracy level only for the 3 seconds interval movie. The implication is that for the accurate identification of the number of blocks offloaded, the movie should at least be recorded at a frame rate of 1 in every 3 seconds. This is expectedly low since offloading of blocks happens relatively quickly and hence for accurate identification, the movie should capture more details.
The trend in the level of accuracy in identifying the number of blocks that were damaged (Fig. 9) during offloading is generally in the same direction as that for the number of block offloaded (Fig. 8). The level of accuracy was constant until the 3 seconds interval time-lapse movie where it rose to the score of 5 (accurate). Again, for accurate identification of the number of damaged blocks, a movie should at least be recorded at a frame rate of 1 in every 3 seconds.

Overall, the results disagree with the allusion by Everett et al. (1998) and Abeid and Arditi (2002b) that an interval frame rate of $1 \mathrm{fps}$ to $5 \mathrm{fps}$ may be adequate for the observation of construction operations. Although Kang and Choi (2005) recommended a frame rate of $1 \mathrm{fpm}$ for the monitoring of productivity with a $70 \%$ level of confidence, the results of this study that relate to labourers suggest that labourers can be tracked accurately from a movie recorded at 1 frame in every 5 minutes.

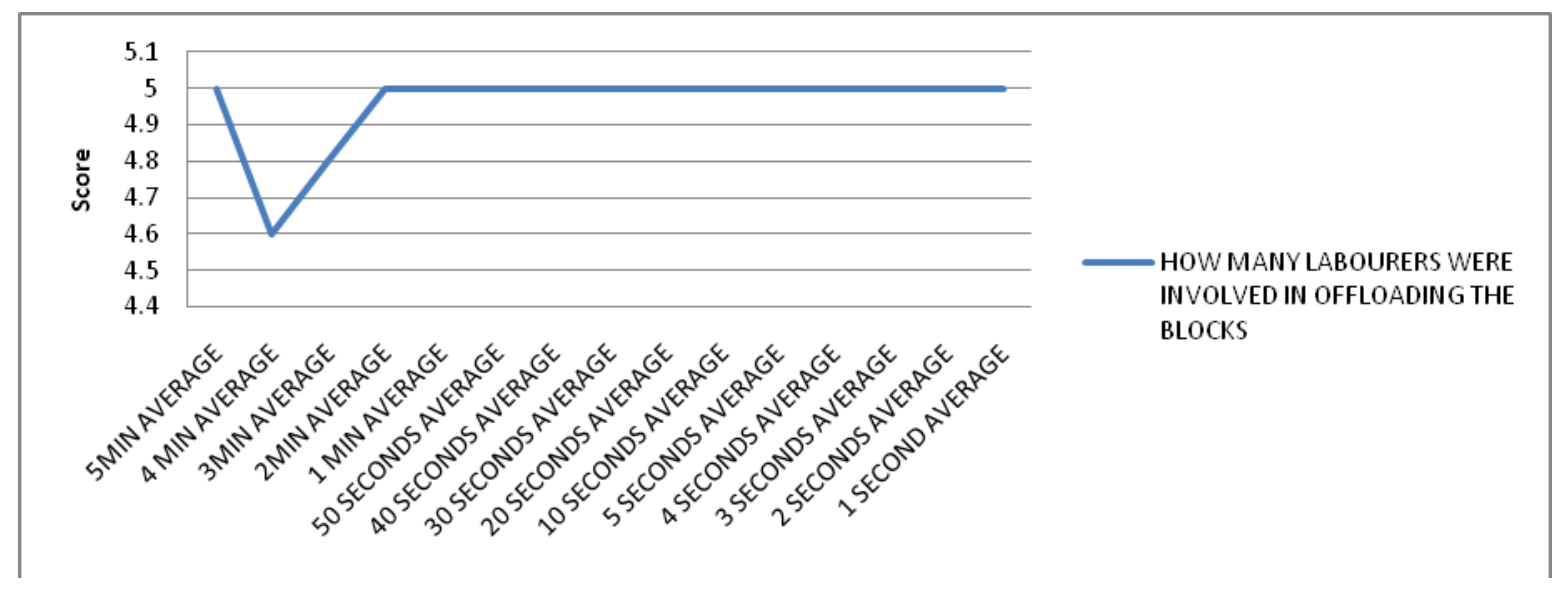

Fig. 7. Number of labourers involved in offloading blocks

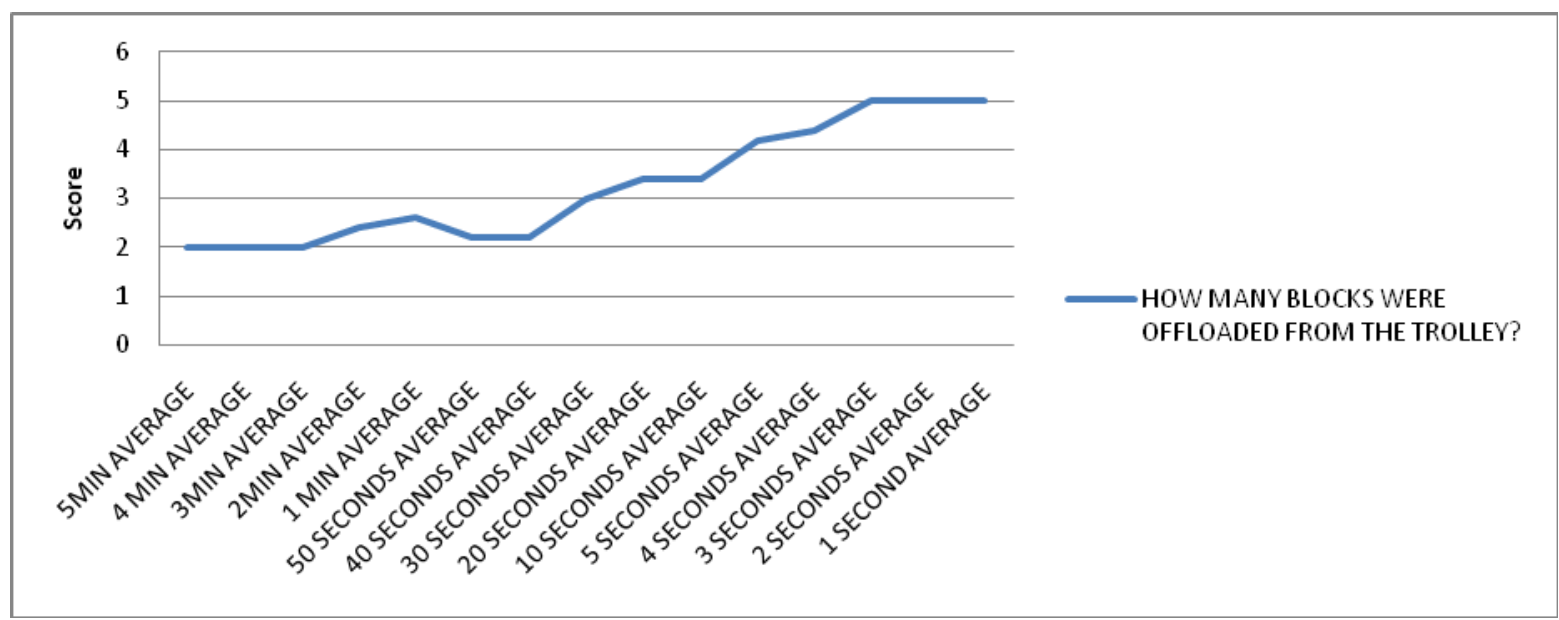

Fig. 8. Number of blocks offloaded from trolley 


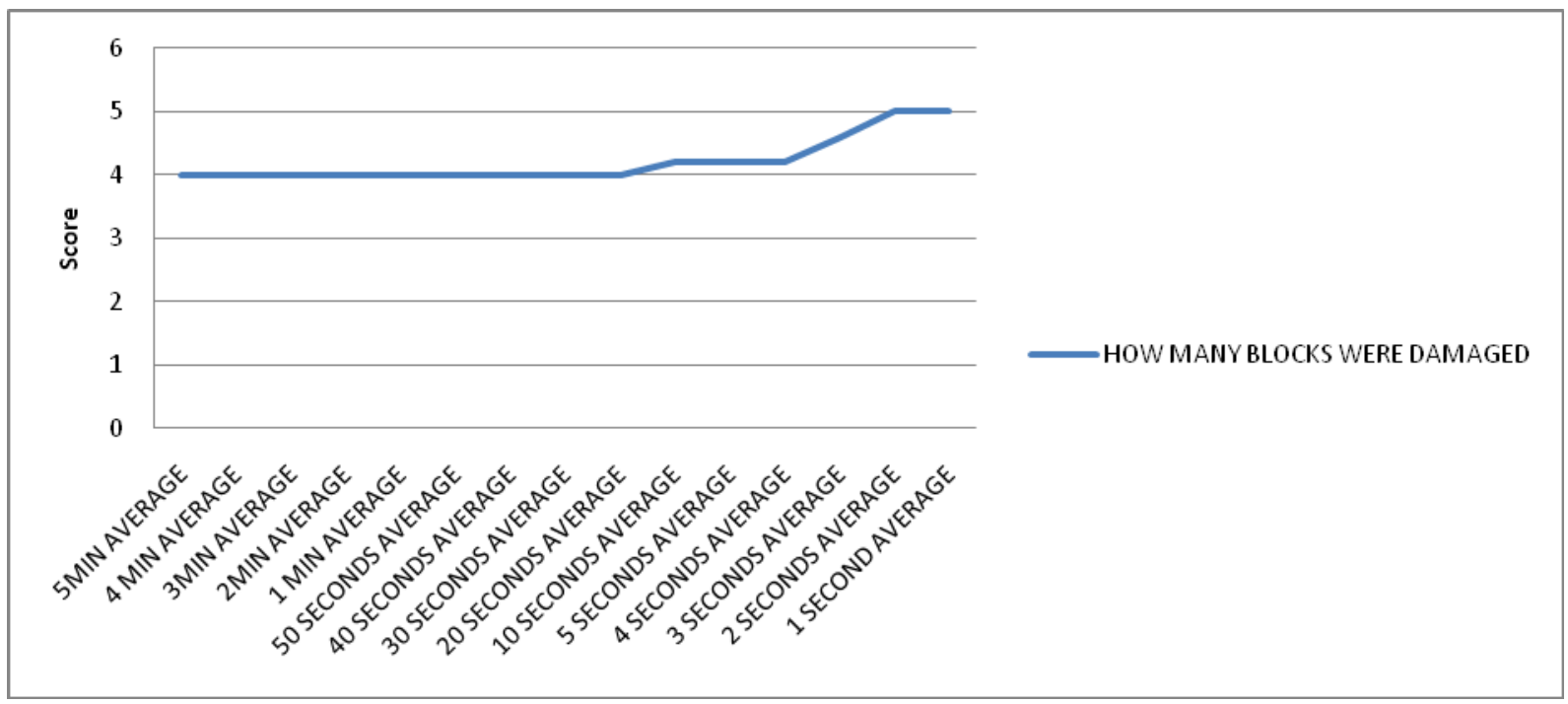

Fig. 9. Number of blocks damaged

\section{Conclusions}

The main objective of the paper was to establish the best frame rate at which time-lapse movies should be recorded so as to enable accurate observation and interpretation mortar mixing and block handling activities. The results suggest that a movie recorded at 1 frame in every 50 seconds is best for the observation of the measure of sand used in mixing mortar. On the other hand, for the accurate identification of the number of cement bags used, a movie recorded at 1 frame in every 20 seconds is best. For keeping accurate track of the number of labourers in mixing mortar, a movie recorded at 1 frame in every 5 minutes is sufficient. As expected, the accurate tracking of number of blocks offloaded or damaged requires a lower frame rate (1 frame in every 2 seconds).

Generally, the results emphasise the fact that accurate observation of various activities require different frame rates. This study only considered a few of these activities. However, our future work will focus on some of the other activities. The authors believe this will pave the way for establishing the optimum frame rate for the observation of entire construction operations.

\section{References}

Abeid, J. and Arditi, D. (2002a). Linking time-lapse digital photography and dynamic scheduling of construction operations. Journal of Computing in Civil Engineering, 16(4), 269-79.

Abeid, J. and Arditi, D. (2002b). Time-lapse digital photography applied to project management. Journal of Construction Engineering and Management, 128(6), 530-535.

Abeid, J and Arditi, D (2003). Photo-net: an integrated system for controlling construction progress. Engineering, Construction and Architectural Management, 10(3), 162-171.

Abeid, J., Allouche, E., Arditi, D., and Hayman, M. (2003). PHOTO-NET II: a computer-based monitoring system applied to project management. Automation in Construction, 12, 603-616.

Bouchlaghem, D., Shang, H., Whyte, J., and Ganah, A., (2005). Visualisation in architecture, engineering and construction (AEC). Automation in Construction, 14, 287-295.

Chau K. W., Anson, M., and Zhang, J. P. (2004). Fourdimensional visualization of construction scheduling and site utilization. Journal of Construction Engineering and Management, 130(4), 598-606.

Everett, J. G., Halkali, H., and Schlaff, T. G. (1998). Time-lapse video applications for construction project management. Journal of Construction Engineering and Management, 124(3), 204-209.

Everett, J. G. and Slocum, A. H. (1993). Cranium: Device improving crane productivity and safety. Journal of Engineering and Management,119(1), 23-39.

Kang, J. and Choi, J. (2005). Observation error of timelapsed photos in construction operation monitoring. Computing in Civil Engineering, 179, (100).

Sampaio, A. Z. and Henriques, P. (2007). Virtual reality models used on the visualisation of construction activities in civil engineering education. International Journal of Social Sciences, 2, 56-61.

Sidawi, B. (2012). Potential use of communications and project management systems in remote construction projects: The case of Saudi Electric Company. Journal of Engineering, Project, and Production Management, 2(1), 14-22.

Staub-French, S. and Khanzode, A. (2007). 3D and 4D modelling for design and construction coordination: Issues and lessons learned, ITcon, 12, 381-407.

Turk, Z. (2001). Multimedia: Providing students with real world experiences. Automation in Construction, Elsevier, 10, 247-255.

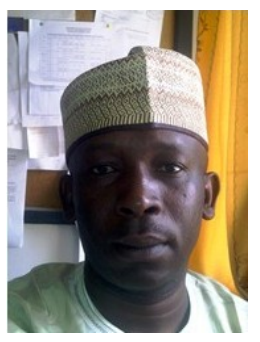

Dr. Ibrahim Yahaya Makarfi is a Senior Lecturer in the department of Quantity Surveying, Ahmadu Bello University, Zaria, Nigeria. He is a member of the Chartered Institute of Building (CIOB), The Association for Project Management (APM) and the Nigerian Institute of Quantity Surveyors (NIQS). His research 
interests are in Information Technology, Project Monitoring and Control and Strategic Management of Construction Firms.

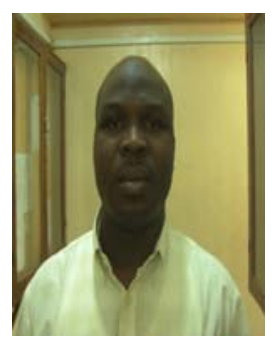

Ibrahim Ahmed Doko is a Senior Lecturer and Head of Quantity Surveying Department, Ahmadu Bello University, Zaria, Nigeria. He holds BSc (Hons) in Quantity Surveying, MSc in Construction Engineering \& Management and $\mathrm{PhD}$ in Construction Project Management. Dr. Ibrahim has research interest in the general areas of Quantity Surveying and Project Management with particular emphasis on Procurement, Cost Modelling, Public-Private Partnerships, Risk Management and Strategic Management of Construction firms. Dr Ibrahim is a corporate member of the Nigerian Institute of Quantity Surveyors, Association for Project Management (UK), Chartered Institute of Building (UK) and the Society for Construction Industry Arbitrators (Nigeria).

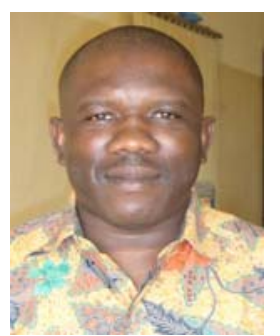

Mr. Chindo Peter Gangas is a Lecturer in the department of Quantity Surveying, Ahmadu Bello University, Zaria, Nigeria. He is a Ph.D candidate in the department of Quantity Surveying, Ahmadu Bello University, Zaria, Nigeria and a member of the Nigerian Institute of Quantity Surveyors (NIQS). His research interests are in Construction Manpower Training and Management, Project Monitoring and Control and Strategic Management of Construction Firms. 